\title{
Service use and cost of mental disorder in older adults with intellectual disability
}

Andre Strydom, Renee Romeo, Natalia Perez-Achiaga, Gill Livingston, Michael King, Martin Knapp and Angela Hassiotis

\section{Background}

The cost of caring for people with intellectual disability currently makes up a large proportion of healthcare spending in western Europe, and may rise in line with the increasing numbers of people with intellectual disability now living to old age.

\begin{abstract}
Aims
To report service use and costs of older people with intellectual disability and explore the influence of sociodemographic and illness-related determinants.
\end{abstract}

\section{Method}

We collected data on receipt and costs of accommodation, health and personal care, physical as well as mental illness, dementia, sensory impairment and disability in a representative sample of adults with intellectual disability aged 60 years and older $(n=212)$.

\section{Results}

The average weekly cost in GBP per older person was $f 790$ (£41080 per year). Accommodation accounted for $74 \%$. Overall costs were highest for those living in congregate settings. Gender, intellectual disability severity, hearing impairment, physical disorder and mental illness had significant independent relationships with costs. Mental illness was associated with an additional weekly cost of £202.

\section{Conclusions}

Older adults with intellectual disability comprise about $0.15-$ $0.25 \%$ of the population of England but consume up to $5 \%$ of the total personal care budget. Interventions that meet needs and might prove to be cost-effective should be sought.

\section{Declaration of interest}

None.
Old age, mental illness and intellectual disability are among the main determinants of healthcare expenditure. ${ }^{1-3}$ In the general population psychiatric disorders influence the cost of care for older adults, and both depression and dementia are significant predictors of high service costs. ${ }^{4}$ The cost of caring for people with intellectual disability currently makes up a large proportion of healthcare spending in western Europe, ${ }^{3}$ and may rise in line with the increasing number of people with intellectual disability now living to old age $;^{5}$ moreover, the rates of mental illness and dementia in people with intellectual disability have been found to be higher than in the general population. ${ }^{6,7}$

There has been no published study of costs of care of a representative sample of older people with intellectual disability. Our study reports service use patterns and costs for older people with intellectual disability in the UK, including accommodation, in-patient and out-patient care, as well as domiciliary and personal care. We predicted that dementia and other psychiatric disorders would be independently associated with increased care costs in this population, and explored the influence of other possible sociodemographic and illness-related determinants.

\section{Method}

We undertook a survey of all adults with intellectual disability without Down syndrome aged 60 years and older living in five inner-city and suburban London boroughs: Camden, Islington, Enfield, Harrow and Greenwich. The study method is described in detail in earlier papers. ${ }^{7,8}$ The Thames Valley multicentre research ethics committee approved the study and it was agreed with the research and development offices of all participating National Health Service (NHS) organisations.

\section{Participants and consent procedures}

All adults with intellectual disability aged 60 years and older, currently resident in any of the five boroughs, were identified from Social Services electronic databases and intellectual disability team healthcare records (current and past recipients of care who have been recorded at any time to have intellectual disability), and from all local residential and day service providers (voluntary or government sector) for adults with intellectual disability.

Informed consent was obtained from participants with intellectual disability who had capacity, but for those who lacked capacity we sought agreement from carers. We also gained consent from informants for their own participation in the survey. Informants were family members, social workers or care staff who had regular contact with the participants. If necessary, further informants or historical records were sought.

\section{Severity of intellectual disability}

Intellectual disability was defined according to ICD-10 criteria for mental retardation as global developmental delay, IQ below 70 and impairment of social functioning. ${ }^{9}$ Those in whom the intellectual disability status was uncertain at screening underwent an assessment and were excluded if they did not meet these ICD-10 criteria. Each participant's severity of intellectual disability was rated to be mild or more severe, according to their early and adult abilities (including IQ score if available).

\section{Physical health}

Information on physical health was obtained from medical records, or from informants in the small number of cases for whom records were not available. We grouped participants into those with one or more chronic health problems and those with 
none. (Chronic health problems were conditions requiring longterm treatment such as cardiovascular disorders, including hypertension; lipid metabolism disorders; respiratory diseases such as chronic obstructive airway disease; arthritic conditions; gastrointestinal disorders such as peptic ulcers and chronic constipation; endocrine disorders such as diabetes; urinary or renal disorders such as chronic urinary tract infection and renal failure; haematological conditions such as anaemia; solid tumours; and neurological conditions such as epilepsy.) Mobility was rated independently of other physical health problems using the Instrumental Activities of Daily Living scale. ${ }^{10}$ Mobility problems were defined as the need to use a railing, cane, frame or wheelchair, or being bedridden.

Hearing ability was assessed with the whispered voice test. ${ }^{11}$ Participants using hearing aids were tested with their aids and hearing was rated as follows: no hearing impairment; can hear speech of normal volume; can only hear loud speech; deaf or near deaf. The screening version of the Kay picture test was used to screen for deficits in visual acuity. ${ }^{12}$ It was designed for children 2-3 years old, and has also successfully been used in adults with intellectual disability. ${ }^{13,14}$ Participants using correction wore their glasses during testing and visual acuity was rated as follows: normal; impaired; blind or almost blind (even after correction).

\section{Mental health and dementia}

Participants were divided into those with and those without a current history (obtained from informants or health records) of one or more serious mental illnesses, including psychoses, affective disorders, anxiety disorders, severe behavioural problems and personality disorders. We did not include a rating for autism-spectrum disorders.

All participants were screened for cognitive or functional decline and memory function. Those who screened positive had a detailed assessment, and the participants were divided into those with and those without a diagnosis of dementia (according to ICD-10, DSM-IV or DC-LD criteria; diagnosis using these criteria has been described in a previous report). ${ }^{7}$

\section{Service use}

All informants were interviewed using the Client Service Receipt Inventory (CSRI) adapted for use in intellectual disabilities. ${ }^{15}$ This collects comprehensive data on a range of demographics and services including usual place of residence, accommodation charges, income and sources of income, and receipt of all healthcare, social care and other services (day care, domiciliary care, respite care and nursing care, in-patient stays, primary and community care contact). Time spent caring by family, other unpaid carers and external providers and aids and adaptations used by study participants were also recorded. We collected data for the preceding 3 months, except for hospital services and aids and adaptations, which covered the previous 6 months. We recorded regular medication use (excluding as needed medication) for the preceding month. Agreement between information collected with the CSRI and general practitioner records has been shown to be relatively high. ${ }^{16}$

\section{Costs}

All costs are expressed as weekly estimates.

Information on the weekly accommodation charges for residential settings came from the manager of the home, or the care manager overseeing the placement. Costs of health and social care were estimated by combining health and social care resource utilisation data with unit costs (2005-6 levels). Unit costs were collected from a variety of national sources. Costs per contact with health and community professionals were taken from an annual national compendium. ${ }^{17}$ Publicly available national reference costs were used to estimate the cost of out-patient attendances. ${ }^{18}$ For some services (accident and emergency, out-patient care and all community-based services) the weekly cost estimate was derived by multiplying the mean number of contacts made with a given service (over 3 months) by the unit cost of contact with service (for each person). The weekly mean cost of that service is estimated by taking the total cost of that service for all patients divided by the total number of service users, divided by 13 weeks. Weekly estimates of hospital-based services were derived in the same way but the costs were weighted by 26 weeks, as hospital service use was based on a 6-month retrospective time-point.

An estimate of the cost of nursing care by external provider to the service user was estimated by multiplying the nursing time spent by the unit cost of a district nurse. ${ }^{17}$ Day activities were estimated by multiplying the appropriate unit of measure consumed in a week by the unit cost of that unit of measure. Costs of informal care were estimated by combining the time spent in domiciliary and personal care by the national minimum hourly wage rate. ${ }^{19}$ Weekly medication costs were estimated by calculating the cost per unit (e.g. per tablet, per volume or per inhaler) at prices quoted in issue 50 of the British National Formulary, ${ }^{20}$ and multiplying this by the actual amount used over the period, except for ointments or creams which were estimated by assuming that the smallest commercially available tube or container was bought every 4 weeks. Missing data on day centre, hospital and community-based services were imputed using the median, to avoid distributional concerns, whereas weekly accommodation charges were estimated using the median charge for individuals living in a similar setting. Data were nearly complete - less than $1.5 \%$ (range $0.5-2.3 \%$ ) of data points were missing. Incomplete medication dosing information was completed using standard dosing regimens if possible. The weekly cost of aids and adaptations was estimated using median annual costs divided by 52. For aids and adaptations not contained in this compendium, costs were estimated by taking the price of the aid, discounting it over 5 years at $3.5 \%$ and dividing by 52 .

\section{Statistical analysis}

Ordinary least squares analysis was used to examine the associations between baseline characteristics and total costs. Bivariate analysis was used to investigate associations between each of the baseline characteristics and the total costs of care, using simple linear regression. Associations between costs and continuous variables were computed. All explanatory variables that had a bivariate association with costs were initially included in the model. Variables that did not have bivariate associations with costs were then included one at a time and were kept if they added significantly to the model. The decision to retain or discard a variable was based on significance at the $10 \%$ level. This approach was chosen as it allowed us to investigate the impact of various potential predictors of costs independently and when all were included in the model. This approach avoids bias due to omitted variables by including not only variables associated with costs in the preliminary analysis, but exploring the importance of other variables.

\section{Results}

We identified and contacted 281 potential participants. Of these, $24(8.5 \%)$ were ineligible for the study. Of the remainder, 222 (86.4\%) participated. The prevalence of eligible participants with 


\begin{tabular}{|c|c|}
\hline \multicolumn{2}{|l|}{ Age, years } \\
\hline Mean & 69 \\
\hline Range & $60-94$ \\
\hline \multicolumn{2}{|l|}{ Ethnicity, $n$ (\%) } \\
\hline Asian/British Asian & $6(3)$ \\
\hline White & $215(97)$ \\
\hline Other & $1(0)$ \\
\hline Male, $n(\%)$ & $117(53)$ \\
\hline \multicolumn{2}{|l|}{ Level of disability, $n$ (\%) } \\
\hline Mild & $123(55)$ \\
\hline Moderate & 70 (32) \\
\hline Severe & $29(13)$ \\
\hline Mental health problem, $n$ (\%) & $93(42)$ \\
\hline Dementia, $n$ (\%) & $29(13)$ \\
\hline Health problem, $n$ (\%) & $183(82)$ \\
\hline Mobility problems, $n$ (\%) & $82(37)$ \\
\hline \multicolumn{2}{|l|}{ Hearing impairment, $n$ (\%) } \\
\hline No hearing impairment & $105(47)$ \\
\hline Conversational voice & $54(24)$ \\
\hline Loud voice & 29 (13) \\
\hline Near deaf & $12(5)$ \\
\hline \multicolumn{2}{|l|}{ Visual impairment, $n$ (\%) } \\
\hline No impairment & $48(22)$ \\
\hline Impaired & $124(56)$ \\
\hline Almost blind & $12(5)$ \\
\hline
\end{tabular}

intellectual disability in the total population of all adults aged 60 years and older was $0.15 \%$. Participants' demographic details are given in Table 1. More than half of the participants $(55.4 \%$, $n=123$ ) were rated as having mild intellectual disability and 99 $(44.6 \%)$ had moderate or more severe intellectual disability; $41.9 \%$ had a mental disorder. Most participants (89.6\%) were dependent on state benefits for their income, but 17 (7.7\%) had income from private sources (such as pension, savings or family support).

Table 2 provides information about the cost of hospital and community services, daytime activities and direct care (if not included in the accommodation costs). In total, 215 (97\%) participants accessed some form of hospital or community service and the cost to agencies was $\mathfrak{E 5 5}$ per week per participant (averaged across the whole sample). Service users accessed a range of community-based services, but the most intensively used were general practitioners and chiropodists. Fifty-one per cent of the sample used at least one hospital-based service, and 95\% used at least one community-based service. Daytime activities (e.g. day centre or social clubs) or respite were accessed by 108 (49\%) of the sample, with the average cost to service providers being $£ 135$ per week. Forty-six (21\%) older adults had domiciliary and personal care provided externally (i.e. not as part of the accommodation package) at an average cost of $£ 17$ per week over the full sample. Although $42 \%$ had a reported psychiatric disorder, just $20 \%$ (less than half of those with mental illness) were receiving input from psychiatrists, $12 \%$ had input from psychiatric nurses and only $4 \%$ had had contact within the past 3 months with a psychologist. The majority of participants $(85 \%)$ were using at least one medication, $59 \%$ of the sample used at least three different types of long-term medication, 94 participants (42\%) used four or more different types of medication, $12(5 \%)$ used eight or more medications and there were $4(2 \%)$ who used nine or more medications.

The total costs of care per week are given in Table 3. Accommodation costs constituted $74 \%$ of the total. Daytime activities and hospital and community healthcare accounted for most of

\begin{tabular}{|c|c|c|}
\hline & $\begin{array}{l}\text { Participants } \\
\text { using service } \\
\text { n (\%) }\end{array}$ & $\begin{array}{l}\text { Weekly } \\
\text { cost, f } \\
\text { Mean (s.d.) }\end{array}$ \\
\hline At least one long-term medication used & $194(87)$ & $0.70(0.93)$ \\
\hline \multicolumn{3}{|l|}{ Hospital-based services } \\
\hline In-patient & $47(21)$ & $20.9(92.4)$ \\
\hline Out-patient & $87(39)$ & $5.2(12.2)$ \\
\hline Accident and emergency & $22(10)$ & $0.9(5.3)$ \\
\hline Total & $114(51)$ & $27.1(94.3)$ \\
\hline \multicolumn{3}{|l|}{ Community-based services } \\
\hline General practitioner & $160(72)$ & $2.4(3.7)$ \\
\hline Psychiatrist & $45(20)$ & $1.7(6.0)$ \\
\hline Clinical psychologist & $9(4)$ & $0.2(1.3)$ \\
\hline Community psychiatric nurse & $27(12)$ & $0.8(3.9)$ \\
\hline Community nurse & $47(21)$ & $1.5(12.2)$ \\
\hline Speech and language therapist & 7 (3) & $0.2(1.6)$ \\
\hline Physiotherapist & $13(6)$ & $0.5(2.9)$ \\
\hline Chiropodist & $137(62)$ & $1.1(1.23)$ \\
\hline Occupational therapist & $18(8)$ & $1.0(7.7)$ \\
\hline Alternative therapist & $21(9)$ & $2.4(9.3)$ \\
\hline Art/drama therapist & $12(5)$ & $1.4(6.6)$ \\
\hline Social worker & $63(28)$ & $0.8(2.3)$ \\
\hline Counsellor & $18(8)$ & $1.0(4.6)$ \\
\hline Dentist & $90(41)$ & $2.5(4.9)$ \\
\hline Dietician & $13(6)$ & $0.5(3.4)$ \\
\hline Family support worker & $14(6)$ & $1.8(7.7)$ \\
\hline voluntary worker & $21(9)$ & $1.7(7.4)$ \\
\hline Befriender & $17(8)$ & $2.6(21.1)$ \\
\hline Meals on wheels & $7(3)$ & $4.1(29.8)$ \\
\hline Total & $210(95)$ & $28.1(45.9)$ \\
\hline \multicolumn{3}{|l|}{ Total hospital and community-based } \\
\hline \multicolumn{3}{|l|}{ Daytime activities } \\
\hline Day centre & $104(47)$ & $125.6(156.2)$ \\
\hline Social club & $8(4)$ & $3.3(21.7)$ \\
\hline Respite care & $6(3)$ & $5.9(41.3)$ \\
\hline Total costs per week & $108(49)$ & $134.8(168.2)$ \\
\hline \multicolumn{3}{|l|}{$\begin{array}{l}\text { Cost of care provided by family } \\
\text { and external providers per week } \\
\text { Care by family }\end{array}$} \\
\hline Domiciliary & $14(6)$ & $2.1(12.9)$ \\
\hline Personal care & $9(4)$ & $1.3(10.8)$ \\
\hline Total & $16(7)$ & $3.4(23.1)$ \\
\hline \multicolumn{3}{|l|}{ Care provided by external providers } \\
\hline Domiciliary & $14(6)$ & $5.1(19.9)$ \\
\hline Personal care & $24(11)$ & $6.1(23.3)$ \\
\hline Nursing care & $3(1)$ & $2.4(23.8)$ \\
\hline Total & $36(16)$ & $13.6(45.7)$ \\
\hline Total costs of care per week & $46(21)$ & $17.0(54.6)$ \\
\hline
\end{tabular}

the remainder. Overall, the average weekly cost in GBP (including accommodation) per older person with intellectual disability was $£ 790$, or $£ 41080$ per year ( $\$ 63176$ in USD or $€ 53548$ in EUR using purchasing power parity at 2006).

The largest proportion of participants were living in residential accommodation $(n=85 ; 38 \%)$, followed by supported living schemes for adults with intellectual disability $(n=38 ; 17 \%)$, nursing homes $(n=30 ; 14 \%)$ and sheltered accommodation schemes (mostly schemes for older people, although some were similar schemes specifically for adults with intellectual disability) $(n=30 ; 14 \%)$. A small proportion of participants were living by themselves in council or privately owned flats, or with family members in private households. Overall costs (including accommodation) were highest for those living in congregate settings such as residential homes ( $\$ 985$ per week) and nursing homes (£910 per week). Most of these costs were for accommodation charges. Lowest costs were for those living in their own homes 
Table 3 Total cost of care per week associated with mental health problems

\begin{tabular}{|lccc|} 
& & Average weekly cost, f: mean (s.d.) \\
\cline { 2 - 4 } & $\begin{array}{c}\text { Full sample } \\
(n=222)\end{array}$ & $\begin{array}{c}\text { Mental health problem } \\
(n=93)\end{array}$ & $\begin{array}{c}\text { No mental health problem } \\
(n=129)\end{array}$ \\
\hline Medication & $0.61(0.95)$ & $0.80(1)$ & $0.48(0.74)$ \\
\hline Accommodation & $582(371)$ & $673(341)$ & $0.3(1)$ \\
\hline Aids and adaptations & $0.3(1)$ & $69(144)$ & $0.2(1)$ \\
\hline Hospital- and community-based care & $55(107)$ & $144(171)$ & $129(68)$ \\
\hline Daytime activities & $135(168)$ & $5(33)$ & $3(12)$ \\
\hline Care by family & $3(23)$ & $12(47)$ & $15(45)$ \\
\hline Care by external providers & $14(46)$ & $904(348)$ & $709(413)$ \\
\hline Total cost of care per week including accommodation & $790(398)$ & $231(234)$ & $193(174)$ \\
\hline Total cost of care per week excluding accommodation & $208(202)$ & & \\
\hline a. Includes behavioural problems, but not dementia. & & & \\
\hline
\end{tabular}

(£203 per week), sheltered accommodation ( $£ 576$ per week), or private households (£648), but non-accommodation elements accounted for all of these costs. A comparison of the costs associated with mental health problems $v$. those without such problems showed that accommodation costs accounted for most of the cost difference (Table 3 ).

We examined demographic and clinical associations (age, gender, severity of intellectual disability, dementia, health problems, mobility problems, mental illness, hearing impairment and visual impairment) of total costs of care, first by using linear regression analysis. Variables that had a bivariate association at $0.5 \%$ with costs (gender, level of disability, whether a hearing assessment was done, presence of health problems, presence of a mental health problem) were initially included in the model. Age, ethnicity, residence, the presence of dementia, mobility problems and visual problems did not have a significant bivariate association with total costs in this sample of older adults with intellectual disability. The best-fitting model shown in Table 4 explained $21 \%$ of the observed variance in cost $\left(R^{2}=0.21\right.$; adjusted $\left.R^{2}=0.19 ; F_{(5,193)}=4.04, P<0.001\right)$. In order of impact, clinical variables that were predictive of cost after adjustment for other explanatory variables included severity of intellectual disability ( $£ 201$ per week for severe intellectual disability relative to mild intellectual disability), hearing impairment ( $£ 25$ per week), presence of health problems ( $\{164$ per week for those with a health problem relative to those without) and presence of mental health problems ( $£ 202$ per week for those with a mental health problem relative to those without).

\section{Discussion}

To our knowledge this is the first detailed study of care costs and service usage of older adults with intellectual disability, including the costs associated with mental illness and dementia. Previous studies of the cost of UK care associated with intellectual disability of the de-institutionalisation process found that costs increased, although simultaneously the quality of life improved on average. $^{21-23}$ As most people lived in supported settings, accommodation accounted for three-quarters of the total costs, with overall costs being lower for those living independently who had, however, higher costs for non-accommodation elements. On average, hospital or other community services constituted a

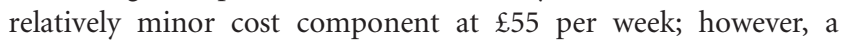
diagnosis of illness was linked to higher costs

\section{Study limitations}

We excluded older adults with Down syndrome, as their needs are better researched than those of people without this syndrome. Very few people with Down syndrome survive beyond the age of 60 years; our estimated costs should therefore be representative of the older intellectual disability population. Although we set out to identify all people with intellectual disability aged 60 years or more, it is possible that we missed individuals not known to intellectual disability services. However, such people are likely to have mild intellectual disability and are unlikely to be using many formal services, and therefore should incur relatively low intellectual disability-associated service costs. A further limitation is our reliance on informant reports and clinical records for information concerning physical and mental health status, rather than undertaking a detailed assessment of participants. Nevertheless, the rates of physical and mental illness in our study were similar to those found in previous studies such as that by Cooper et al. ${ }^{6}$ Although we made a detailed assessment of costs and service use, it is possible that some elements relevant to overall costs were not as accurate as we would have liked; for example, we used

\begin{tabular}{lccc|} 
Table 4 Predictors of total cost of care & & & \\
& & Standard error & \\
Constant & 317.97 & 92.72 & 0.001 \\
\hline Gender: relative to male & 84.69 & 51.98 & 0.105 \\
\hline Level of intellectual disability: relative to mild intellectual disability & 200.98 & 42.75 & $<0.001$ \\
\hline Hearing impairment: relative to no impairment & 25.05 & 28.61 & $\mathrm{NS}$ \\
\hline Health problem: relative to no health problem & 163.66 & 68.07 & 0.017 \\
\hline Mental health problem: relative to no mental health problem & 201.82 & 51.50 & $<0.001$ \\
\hline Goodness of fit statistics & $R^{2}=0.21 ;$ adjusted $R^{2}=0.19 ; F_{(5,193)}=4.04(P<0.01)$ \\
\hline NS, not significant. & & & \\
\hline
\end{tabular}


average costs in residential care settings, not the actual individual cost of care.

\section{Cost of intellectual disability and ageing}

We did not demonstrate a relationship between age and cost, possibly because the lifelong, complex disability associated with intellectual disability means that people have longstanding care needs and the additional problems of ageing do not add significantly to this. Furthermore, those with most severe intellectual disability tend to die younger, ${ }^{24}$ so that those who are older might be relatively healthy. ${ }^{25}$ In addition, there are several other possible contributors to costs that we have not accounted for, such as provider characteristics, ${ }^{26}$ market structure, price-cost mark-up or subsidisation of charges, and the purchasing power of local authorities and local NHS commissioners. ${ }^{27}$ Costs for older people with mental health needs in the general population rise with age, probably owing to increasing physical disability; but it has been found that, if those above and below age 65 years are considered, the support costs in relation to need are lower for the older people. ${ }^{28}$ As in our study, higher costs and service use in younger people in care accommodation in England are associated with more severe intellectual disability and more challenging behaviour, ${ }^{29}$ but vary widely according to models of accommodation, individual organisations, settings and service users. Direct comparison of specific accommodation types have shown that semi-independent living may offer cost and quality of life benefits compared with fully staffed homes. ${ }^{30}$

\section{Dementia and mental illness costs in older adults with intellectual disability}

If dementia is included, psychiatric morbidity rates are raised in older, compared with younger, adults with intellectual disability. ${ }^{31}$ Dementia did not predict higher costs in this study. In the general older adult population, dementia is the most expensive psychiatric disorder in older adults owing to high personal Social Services costs. ${ }^{32}$ However, having dementia was a negative predictor of health service use, ${ }^{32}$ and therefore not always associated with high healthcare costs. As with age, dementia may not lead to increased costs in the intellectual disability population as people are often already living in supported accommodation with personal Social Services and so do not use additional resources. Alternatively, they may have unmet needs because dementia is often undiagnosed and unmanaged. ${ }^{7}$ Previous studies have found that mental illness, especially depression, significantly increases service costs in older adults in general. ${ }^{4}$ Mental health problems occurred frequently in our sample of older adults with intellectual disability, and a diagnosis of mental illness was the most prominent clinical predictor of costs. However, there was a relative lack of healthcare, suggesting ample scope to improve healthcare without making major additional demands on overall costs, thus possibly leading to reduced needs for long-term care and care costs.

\section{Comparison with personal Social Services budget in England}

During 2006-7, $£ 3.3$ billion of the $£ 20$ billion ( 1 billion $=10^{9}$ ) spent on personal Social Services in England was used to support adults aged under 65 years with intellectual disability. ${ }^{33}$ Similarly, in The Netherlands, nearly $10 \%$ of the care budget is used for people with intellectual disability. ${ }^{3}$ Older adults with intellectual disability make up only a small proportion of the older population $(0.15-0.25 \%) ;{ }^{34}$ using our figures, the cost of providing social care to them is between $\mathfrak{E} 595$ million and nearly $\mathfrak{E} 1$ billion, which is up to $5 \%$ of the total budget. Even small increases in the population of older adults with intellectual disability may therefore have considerable overall cost implications.

\section{Implications}

Older adults with intellectual disability are a growing population who consume a significant, disproportionate and increasing proportion of resources, although perhaps less than their morbidity levels would suggest is equitable according to need. Their frailty in old age may be underestimated, or subsumed into existing provision. We have demonstrated that mental illness, severity of disability and health problems are important predictors of costs; these characteristics should therefore be taken into consideration when planning resource allocation and service development at a local level. Services and funders should ensure equal access to care and support, regardless of age, and consider family carers. Nevertheless, there may also be opportunities to improve care without large increases in overall spend, which could result in cost reduction in the longer term, by early identification and management of mental illness or behavioural problems, which could lead to placement in less restrictive and less costly environments. This is in keeping with the principles of the UK government strategy for the care of adults with intellectual disability, ${ }^{35,36}$ which emphasises the need to reduce costly placements (often out of area) by ensuring access to appropriate specialist support, local accommodation options, education and day opportunities.

\begin{abstract}
Andre Strydom, MRCPsych, MSC, PhD, Department of Mental Health Sciences, University College London Medical School, and Camden and Islington Foundation NHS Trust, London; Renee Romeo, MSc, Centre for the Economics of Mental Health, King's College London, Institute of Psychiatry; Natalia Perez-Achiaga, MRCPsych, MSc, Community Learning Disabilities Team, Royal Borough of Kensington and Chelsea, London; Gill Livingston, FRCPsych, MD, Department of Mental Health sciences, University College London Medical School, and Camden and Islington Foundation NHS Trust, London; Michael King, MD, PhD, FRCP, FRCGP, FRCPsych, Department of Mental Health Sciences, University College London Medical School; Martin Knapp, PhD, Personal Social Services Research Unit, London School of Economics, and Centre for the Economics of Mental Health, King's College London, Institute of Psychiatry; Angela Hassiotis, MA, PhD, FRCPsych, Department of Mental

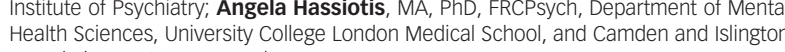
Foundation NHS Trust, London, UK
\end{abstract}

Correspondence: Dr Andre Strydom, Department of Mental Health Sciences, University College London, 67-78 Riding House Street, London W1W 7EY, UK. Email: a.strydom@ucl.ac.uk

First received 3 Nov 2008, final revision 12 Oct 2009, accepted 21 Oct 2009

\section{References}

1 Meerding WJ, Bonneux L, Polder JJ, Koopmanschap MA, van der Maas PJ. Demographic and epidemiological determinants of healthcare costs in Netherlands: cost of illness study. BMJ 1998; 317: 111-5.

2 Polder JJ, Bonneux L, Meerding WJ, van der Maas PJ. Age-specific increases in health care costs. Eur J Public Health 2002; 12: 57-62.

3 Polder JJ, Meerding WJ, Bonneux L, van der Maas PJ. Healthcare costs of intellectual disability in the Netherlands: a cost-of-illness perspective. J Intellect Disabil Res 2002; 46: 168-78.

4 Livingston G, Manela M, Katona C. Cost of community care for older people. Br J Psychiatry 1997; 171: 56-9.

5 Holland AJ. Ageing and learning disability. Br J Psychiatry 2000; 176: 26-31.

6 Cooper SA, Smiley E, Morrison J, Williamson A, Allan L. Mental ill-health in adults with intellectual disabilities: prevalence and associated factors. Br J Psychiatry 2007; 190: 27-35.

7 Strydom A, Livingston G, King M, Hassiotis A. Prevalence of dementia in intellectual disability using different diagnostic criteria. Br J Psychiatry 2007; 191: $150-7$.

8 Strydom A, Hassiotis A, King M, Livingston G. The relationship of dementia prevalence in older adults with intellectual disability (ID) to age and severity of ID. Psychol Med 2009; 39: 13-21 
9 World Health Organization. The ICD-10 Classification of Mental and Behavioural Disorders. WHO, 1992.

10 Lawton MP, Brody EM. Assessment of older people: self-maintaining and instrumental activities of daily living. Gerontologist 1969; 9: 179-86.

11 Pirozzo S, Papinczak T, Glasziou P. Whispered voice test for screening for hearing impairment in adults and children: systematic review. BMJ 2003; 327: 967.

12 Kay H. New method of assessing visual acuity with pictures. Br J Ophthalmol 1983; 67: 131-3.

13 Prasher V. Screening of ophthalmic pathology and its associated effects on adaptive behaviour in adults with Downs syndrome. Eur J Psychiatry 1994; 8 197-204.

14 Woodhouse JM, Griffiths C, Gedling A. The prevalence of ocular defects and the provision of eye care in adults with learning disabilities living in the community. Ophthalm Physiol Opt 2000; 20: 79-89.

15 Beecham J, Knapp M. Costing psychiatric interventions. In Measuring Mental Health Needs 2nd ed (ed G Thornicroft): 200-24. Gaskell, 2001.

16 Byford S, Leese $M$, Knapp M, Seivewright $H$, Cameron S, Jones $V$, et al. Comparison of alternative methods of collection of service use data for the economic evaluation of health care interventions. Health Econ 2007; 16: 531-6.

17 Curtis L, Netten A. Unit Cost of Health and Social Care 2006. Personal Social Services Research Unit, 2006.

18 Department of Health. NHS Reference Costs. UK Department of Health, 2006.

19 Incomes Data Services. The National Minimum Wage. Thomson Sweet \& Maxwell, 2006.

20 British Medical Association, Royal Pharmaceutical Society of Great Britain. British National Formulary (September issue). BMJ Books \& Pharmaceutical Press, 2005.

21 Beecham J, Knapp M, McGilloway S, Donnelly M, Kavanagh S, Fenyo A, et al The cost-effectiveness of community care for adults with learning disabilities leaving long-stay hospital in Northern Ireland. J Intellect Disabil Res 1997; 41 : 30-41.

22 Dockrell JE, Gaskell GD, Normand C, Rehman H. An economic analysis of the resettlement of people with mild learning disabilities and challenging behaviour. Soc Sci Med 1995; 40: 895-901.
23 Hallam A, Beecham J, Knapp M, Carpenter J, Cambridge P, Forrester-Jones R, et al. Service use and costs of support 12 years after leaving hospital. J Appl Res Intellect Disabil 2006; 19: 296-308.

24 Patja K, Mölsä $P$, livanainen M. Cause-specific mortality of people with intellectual disability in a population-based, 35-year follow-up study. J Intellect Disabil Res 2001; 45: 30-40.

25 Janicki MP, Davidson PW, Henderson CM, McCallion P, Taets JD, Force LT, et al. Health characteristics and health services utilization in older adults with intellectual disability living in community residences. J Intellect Disabil Res 2002; 46: 287-98.

26 Matosevic T, Knapp M, Le Grand J. Motivation and commissioning: perceived and expressed motivations of care home providers Soc Policy Adm 2008; 42 : 228-47.

27 Knapp M, Hardy B, Forder J. Commissioning for quality: ten years of social care markets in England. J Soc Policy 2001; 30: 13.

28 Beecham J, Knapp M, Fernandez JL, Huxley P, Mangalore R, Mccrone P, et al. Age Discrimination in Mental Health Services. Personal Social Services Research Unit, 2008.

29 Knapp M, Comas-Herrera A, Astin J, Beecham J, Pendaries C. Intellectual disability, challenging behaviour and cost in care accommodation: what are the links? Health Soc Care Community 2005; 13: 297-306.

30 Felce D, Perry J, Romeo R, Robertson J, Meek A, Emerson E, et al. Outcomes and costs of community living: semi-independent living and fully staffed group homes. Am J Ment Retard 2008; 113: 87-101.

31 Cooper SA. Epidemiology of psychiatric disorders in elderly compared with younger adults with learning disabilities. Br J Psychiatry 1997; 170: 375-80.

32 Nelson T, Fernandez JL, Livingston G, Knapp M, Katona C. Does diagnosis determine delivery? The Islington study of older people's needs and health care costs. Psychol Med 2004; 34: 147-55.

33 UK National Statistics. Personal Social Services Expenditure and Unit Costs, 2006-07. Information Centre for Health and Social Care, 2008.

34 Emerson E, Hatton C. Estimating the Current Need/Demand for Supports for People with Learning Disabilities in England. Institute of Health Research, University of Lancaster, 2004.

35 Department of Health. Valuing People: A New Strategy for Learning Disability for The 21st Century. Department of Health, 2001.

36 Department of Health. Commissioning Specialist Adult Learning Disability Health Services. Good Practice Guidance. Department of Health, 2007. 